\title{
Friction between a surrogate skin (Lorica Soft) and nonwoven fabrics used in hygiene products
}

\author{
Sabrina S Falloon and Alan Cottenden \\ University College London \\ Department Medical Physics \& Biomedical Engineering, Malet Place Engineering \\ Building, Gower Street, London WC1E 6BT \\ sabrina.falloon.10@ucl.ac.uk \\ a.cottenden@ucl.ac.uk
}

\begin{abstract}
Incontinence pad wearers often suffer from sore skin, and a better understanding of friction between pads and skin is needed to inform the development of less damaging materials. This work investigated friction between a skin surrogate (Lorica Soft) and 13 nonwoven fabrics representing those currently used against the skin in commercial pads. All fabrics were found to behave consistently with Amontons' law: coefficients of friction did not differ systematically when measured under two different loads. Although the 13 fabrics varied considerably in composition and structure, their coefficients of friction (static and dynamic) against Lorica Soft were remarkably similar, especially for the 10 fabrics comprising just polypropylene (PP) fibres. The coefficients of friction for one PP fabric never differed by more than $15.7 \%$ from those of any other, suggesting that the ranges of fibre decitex (2.0-6.5), fabric area density (13-30 g. $\left.\mathrm{m}^{-2}\right)$ and bonding area (11-25\%) they exhibited had only limited impact on their friction properties. It is likely that differences were largely attributable to variability in properties between multiple samples of a given fabric. Of the remaining fabrics, the one comprising polyester fibres had significantly higher coefficients of friction than the highest friction polypropylene (PP) fabric, while the one comprising PP fibres with a polyethylene (PE) sheath had significantly lower coefficients of friction than the lowest friction PP fabric. However, fabrics differed in too many other ways to confidently attribute these differences in friction properties just to the choice of base polymer.
\end{abstract}

\section{Introduction}

Urinary incontinence is very common. It is estimated that $10 \%$ of women in the western world suffer from it weekly, while a further 25-45\% also leak, but less frequently (Milsom et al, 2013). Prevalence increases with age (Milsom et al, 2013; Hunskaar et al, 2005), and figures for men are around half of those for women. Treating the underlying causes of urinary incontinence using behaviour therapy, medication, or surgery can often achieve cure - or, at least, a reduction in the severity of symptoms. However, complete cure is not always possible, and for those not fully cured, the challenge is to discover how to manage their incontinence so as to minimize its impact on their quality of life. This usually involves using some kind of continence product(s) to control or contain leakage, and disposable absorbent pads are by far the most common.

Disposable incontinence pads have improved considerably in recent years but wearers still commonly experience skin damage, soreness and discomfort in the diaper area (Clarke-O'Neill et al, 2015). When skin is occluded by pad materials - especially if they are wet - the outer-most layer of the skin (the stratum corneum) becomes overhydrated, compromising its barrier function and making it susceptible 
to abrasion damage by friction against the pad, and vulnerable to chemical irritation and bacterial colonisation (Lyder et al, 1992; Berg et al, 1988; Ersser et al, 2005). The aim of the work described here was to investigate friction between a skin surrogate (Lorica Soft) and a wide range of nonwoven materials representative of those currently used next to the skin in commercially available incontinence pads.

\section{Background and literature review}

Incontinence pads vary greatly in the detail of their design but they are invariably based on an absorbent core sandwiched between a waterproof backsheet below and a water-permeable topsheet next to the skin. Topsheets are usually made from nonwoven fabrics - open-structured, fibrous materials which help to stabilize the absorbent core, readily allow urine through to the absorbent core and, ideally, resist its escape in the reverse direction. The formal definition of a nonwoven is, "... a sheet of fibres, continuous filaments, or chopped yarns of any nature or origin, that have been formed into a web by any means, and bonded together by any means, with the exception of weaving or knitting." (EDANA, 2008).

Nonwovens can be formed and bonded in a variety of ways. Spunbonding refers to the process of converting molten polymer granules to filaments - by extrusion via spinnerets - and then cooling them before they are laid to create a uniform web. Some bonding initially occurs due to cohesion between touching fibres before they have fully cooled. Carding refers to the creation of a web of fibres from fibre bales which are opened, combined and transported by an air stream to one or more rotating drums (or cards). These drums radiate narrow wiry projections or teeth, which act as a comb, spreading the fibres to form the web. Calendering is the process of mechanically stabilizing a fabric by compressing it between hot rolls with raised patterns on their faces that deliver a regular array of pressure points to the fabric, causing localized melting (bonding) together of fibres. For bicomponent fibres, the fibre mat is heated to a temperature between the softening-temperatures of the two component materials, so that bonding is promoted between the sheaths of contacting fibres, while the less affected cores enable the fibres to retain mechanical integrity throughout the process.

Incontinence-associated (or perineal) dermatitis (IAD) occurs when the skin comes into contact with urine and/or faeces for prolonged periods of time, resulting in localized inflammation of the skin, and a common context is skin occluded by absorbent or other incontinence products (Gray, 2010). Most prevalence studies have been conducted on elderly populations in long-term care facilities and figures of 3.5-53\% have been reported (Cottenden et al, 2013). In recent years, much work has been done to investigate the diagnosis and treatment of IAD, but less research has focused on identifying and understanding the mechanisms that cause it. In particular, the contribution of friction between skin and incontinence pad topsheets is currently unclear.

There have been many studies of friction between skin and monolithic hard materials such as glass (Derler and Rotaru, 2013; Adams et al, 2007), various metals (Veijgen et al, 2012; Veijgen et al, 2013; Tomlinson et al, 2011; Kwiatkowska et al, 2009) and various polymers (Veijgen et al, 2013; Tomlinson et al, 2011; Elsner et al, 1990; Cua et al, 1990) but friction between fabrics and skin - or skin surrogates - has received relatively little attention. In work to date, two main approaches have been taken. In the first, a circular probe or annulus, faced with the fabric of interest, is pressed against the skin (surrogate) while the torque required to rotate it about its axis is measured (Zhang and Mak, 1999). By contrast, in the second - linear pull - method, the force required to translate the fabric across the skin (surrogate) under load is recorded (Cottenden et al, 2008a\&b; Gerhardt et al, 2008a, 2009a; Derler et al, 2007; Gwosdow et al, 1986; Kenins, 1994; Hong et al, 2005; Comaish and Bottoms, 1971; Derler and Rotaru, 2013). Linear pull methods can be further divided into straight pull methods, in which the translation is in a straight line across a flat surface (Cottenden et al, 2008a; Gerhardt et al, 2008a, 2009a; Derler et al, 2007; Hong et al, 2005; Comaish and Bottoms, 1971), and curved pull methods, in which a strip of the fabric is draped under load over a curved skin (surrogate) surface and is dragged along a path corresponding to a geodesic of the curved surface (Cottenden et al, 2008b; Gwosdow et al, 1986; Kenins, 1994). Sometimes, straight linear pull methods are implemented using a force plate which 
Friction between a surrogate skin (Lorica Soft) and nonwoven fabrics used in hygiene products

simultaneously records normal and friction forces as a function of time (Derler and Rotaru, 2013; Gerhardt et al, 2008b, 2009b; Derler et al, 2007, 2009).

The work reported here draws on investigations by Cottenden and Cottenden (2013) who developed a straight pull method for measuring friction between a skin surrogate (Lorica Soft) and nonwovencovered acrylic anvils. Lorica Soft was chosen as skin surrogate because Derler et al (2007) demonstrated that its coefficient of friction against a test fabric was similar to that for skin for normal loads from almost nothing to about $10 \mathrm{~N}$. The anvils were cast to have shapes such as to ensure uniform pressure across nonwoven $\sim$ Lorica Soft interfaces for each particular load. Two such interfaces were used in order to substantially avoid the complexities that would have been generated by the turning moment, to which the assembly would have been subjected if only one friction surface were present. With just one interface, the line of action of the tensometer force would be vertically displaced from the plane of the Lorica Soft fabric interface.

In their work to develop the methodology, Cottenden and Cottenden (2013) took measurements using five different normal loads $(0.25 \mathrm{~N}, 0.73 \mathrm{~N}, 2.65 \mathrm{~N}, 8.09 \mathrm{~N}$ and $19.01 \mathrm{~N})$ - to generate pressures spanning the range thought to occur between skin and pads in real use - and five different tensometer crosshead speeds $\left(0.05 \mathrm{~mm} . \mathrm{s}^{-1}, 0.167 \mathrm{~mm} . \mathrm{s}^{-1}, 0.5 \mathrm{~mm} \cdot \mathrm{s}^{-1}, 1.67 \mathrm{~mm} . \mathrm{s}^{-1}\right.$ and $\left.5 \mathrm{~mm} . \mathrm{s}^{-1}\right)$. However, they found that coefficients of friction did not vary systematically with normal load, and that, although they did find a measurable variation with crosshead speed, the magnitude was low. They also discovered that Amontons' law held to high precision for dry friction for each of three nonwoven fabrics and pressures between $0.6 \mathrm{kPa}$ and $32.1 \mathrm{kPa}$ (loads between $0.25 \mathrm{~N}$ and $19.01 \mathrm{~N}$ on anvils $26 \mathrm{~mm}$ in diameter); that is, coefficients of (dynamic) friction were independent of normal load.

The primary aim of the work described here was to extend Cottenden and Cottenden's earlier experiments (2013) by using their method to investigate dry friction for a wider range of nonwovens of the kind currently used to face commercially available disposable body-worn incontinence pads. A second aim was to generate data that would help with selecting a suitable subset of fabrics for future work on the skin of volunteers. An ideal strategy might have been to specify a set of experimental fabrics that differed from one another in limited and well-defined ways, so facilitating a systematic study of the impact of different polymer and manufacturing variables on fabric friction properties, but this would have been impractical. Nonwovens for use in incontinence products are generally made in vast quantities using high speed processes, and the number of - often interdependent - process variables is considerable. Nevertheless, it was possible to select a series of 13 fabrics, such that useful comparisons could be made between fabrics which held some features in common while differing in others.

\section{Materials and methods}

Table 1 summarizes the primary features and manufacturing details of the 13 nonwovens chosen for the work, along with the three used by Cottenden and Cottenden (2013) in their earlier work, for comparison. These three were also added to the mix in preliminary work to provide cross-checking in the initial stages.

Table 1. Manufacturing processes and key features of the 13 nonwoven fabrics investigated (coded SF*), and the three used in Cottenden and Cottenden's (2013) earlier work (coded DC*). All information was obtained from the manufacturer; missing information is indicated with a '-'.

\begin{tabular}{llcccll}
\hline $\begin{array}{l}\text { Fabric } \\
\text { Code }\end{array}$ & Fibre Polymer & $\begin{array}{c}\text { Fibre } \\
\text { Decitex }\end{array}$ & $\begin{array}{c}\text { Nominal } \\
\text { Fabric Area } \\
\text { Density / g.m }{ }^{-2}\end{array}$ & $\begin{array}{c}\text { Fabric } \\
\text { Bonding } \\
\text { Area }\end{array}$ & Fabric Manufacturing & $\begin{array}{l}\text { Nature of } \\
\text { Surfactant }\end{array}$ \\
\hline DC1 & PP & 2.0 & 17 & $12 \%$ & Spunbond and calendered & - \\
\hline DC3 & PP & 1.4 & 17 & $12 \%$ & Spunbond and calendered & - \\
\hline DC6 & PP & 3.6 & 17 & $12 \%$ & Spunbond and calendered & - \\
\hline SF1 & PP & 2.0 & 18 & $18 \%$ & Spunbond and calendered & None \\
\hline SF2 & PP & 2.0 & 18 & $11 \%$ & Spunbond and calendered & None \\
\hline
\end{tabular}


Friction between a surrogate skin (Lorica Soft) and nonwoven fabrics used in hygiene products

\begin{tabular}{llcccll} 
SF3 & PET & 1.7 & 50 & N/A & Carded and spunlaced & - \\
\hline SF7 & PP & 2.5 & 20 & - & Spunbond and calendered & None \\
\hline SF9 & PP & 6 & 20 & $12 \%$ & Spunbond and calendered & Hydrophilic \\
\hline SF10 & PP & - & 18 & - & Spunbond and calendered & None \\
\hline SF11 & PP & 2.2 & 18 & $25 \%$ & Carded and calendered & - \\
\hline SF12 & PP & 2.2 & 30 & $25 \%$ & Carded and calendered & Hydrophilic \\
\hline \multirow{2}{*}{ SF14 } & PP 95\%, & $1.7^{\mathrm{b}}$ & 30 & $25 \%$ & Carded and calendered & - \\
\hline SF15 & PP & 2.0 & 13 & $18 \%$ & Spunbond and calendered & None \\
\hline SF16 & PP & 2.0 & 25 & $18 \%$ & Spunbond and calendered & None \\
\hline SF17 & PP & 6.5 & 17 & $12 \%$ & Spunbond and calendered & - \\
\hline SF18 & PE/PP S/C bico & 1.5 & 15 & $12 \%$ & Spunbond and calendered & Hydrophilic \\
\hline
\end{tabular}

${ }^{\text {a }} \mathrm{PE} / \mathrm{PP} \mathrm{S} / \mathrm{C}$ bico 30/70 refers to the 30:70 mass ratio of PE sheath to PP core in these bicomponent fibres.

b The 1.7 decitex refers to the PP fibres only.

${ }^{c}$ Not applicable: this fabric was not bonded by melting fibres together.

Most of the 13 fabrics had been manufactured either by spunbonding and calendering (9/13) - like the fabric shown in figure 1 - or by carding and calendering (3/13). The fraction of the fabric area included in bonding varied from $11 \%$ to $25 \%$ between the 12 fabrics manufactured in this way. The thirteenth fabric (SF3) was spunlaced (hydroentangled), meaning that it was bonded using fine water jets at high pressure to entangle and enmesh the fibres. Due to the intrinsic hydrophobicity of the constituent polymers, uncoated nonwoven fibres remained hydrophobic.

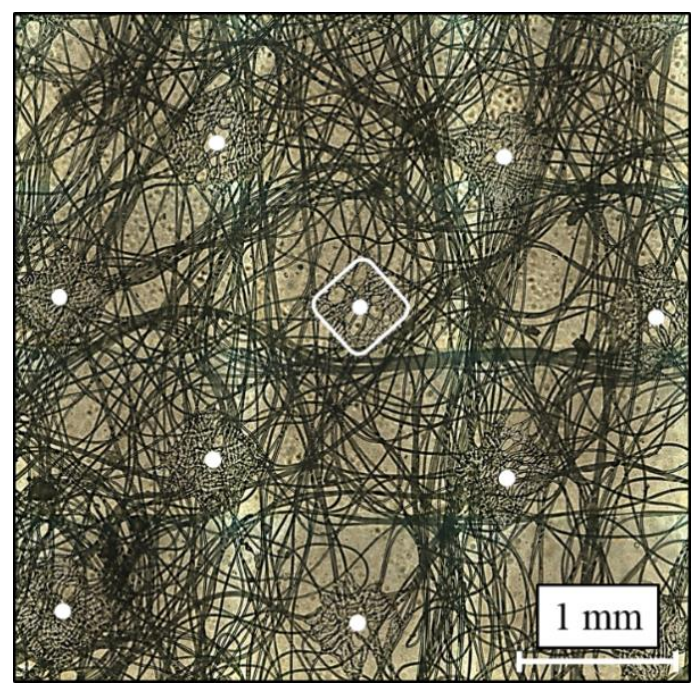

Figure 1. Micrograph of an example nonwoven fabric (SF18) showing the array of bonding points used to stabilize the fabric. Bonding points (one is outlined for clarity) were square (around $0.5 \mathrm{~mm} \mathrm{x}$ $0.5 \mathrm{~mm}$ ) and in rows and columns spaced roughly $1.4 \mathrm{~mm}$ between centres (indicated by white dots).

Ten of the 13 fabrics were made from polypropylene (PP) fibres, while SF3 used polyester (PET) fibres, and the predominantly PP fibres in SF14 were supplemented with 5\% of cotton fibres. Fabric SF18 was made from bicomponent fibres comprising a higher softening-temperature PP core surrounded by a lower softening-temperature polyethylene (PE) sheath. The decitex of the fibres (mass in grams per 10 $\mathrm{km}$ of a fibre) in around half of the 13 fabrics was 2 or 2.2, while the fibres were finer in three fabrics (down to 1.5 decitex for SF18) and coarser in a further three (up to 6.5 decitex for SF17). Most of the fabrics (7/13) had nominal area densities between 17 and $20 \mathrm{~g} . \mathrm{m}^{-2}$, while four were denser (up to 50 g.m $\mathrm{m}^{-2}$ for SF3), and a further two, lighter (down to $13 \mathrm{~g} \cdot \mathrm{m}^{-2}$ for SF15).

Friction was measured between Lorica Soft (Ehrlich Lederhandels GmbH, Biberach, Germany; http://www.ehrlich-leder-lorica.de) and each of the 13 chosen fabrics (table 1) using a method based on that devised by Cottenden and Cottenden (2013) and the apparatus shown in figure 2. A tensometer was 
used to pull a slider bearing two Lorica Soft surfaces (one facing upwards and the other down) between a pair of cast acrylic anvils covered in the nonwoven of interest, secured at the periphery of each anvil with varnish. Loads were applied using dead weights (figure 2). Before these dead weights were applied, a small "trimming" load was added to the upper Perspex support to compress the four springs, so that the nonwoven on the top anvil was just in contact with the upper surface of the slider. The springs counterbalanced the weight of the upper Perspex support and trimming load so that the only force applied to the upper nonwoven $\sim$ Lorica Soft interface was the chosen applied normal load. All measurements were carried out in an environmentally controlled room (maintained at $23.0 \pm 2{ }^{\circ} \mathrm{C}$ and $50.0 \pm 4 \%$ relative humidity), where the skin surrogate samples remained throughout the experimental period.

Two Lorica Soft $\sim$ fabric interfaces were used, positioned symmetrically about the line of the tensometer pull. The tensometer force was logged for displacements up to $50 \mathrm{~mm}$ as the slider was pulled from its initial position, and the initial maximum force generated was taken to be that required to overcome static friction between the Lorica Soft and the fabric, having divided by two to take account of the two interfaces. To estimate the force required to overcome dynamic friction, the mean tensometer force for displacements between $12 \mathrm{~mm}$ and $50 \mathrm{~mm}$ was calculated. Following Cottenden and Cottenden's (2013) practice data, the initial $12 \mathrm{~mm}$ of motion were discarded to avoid the transition phase from static to dynamic friction.

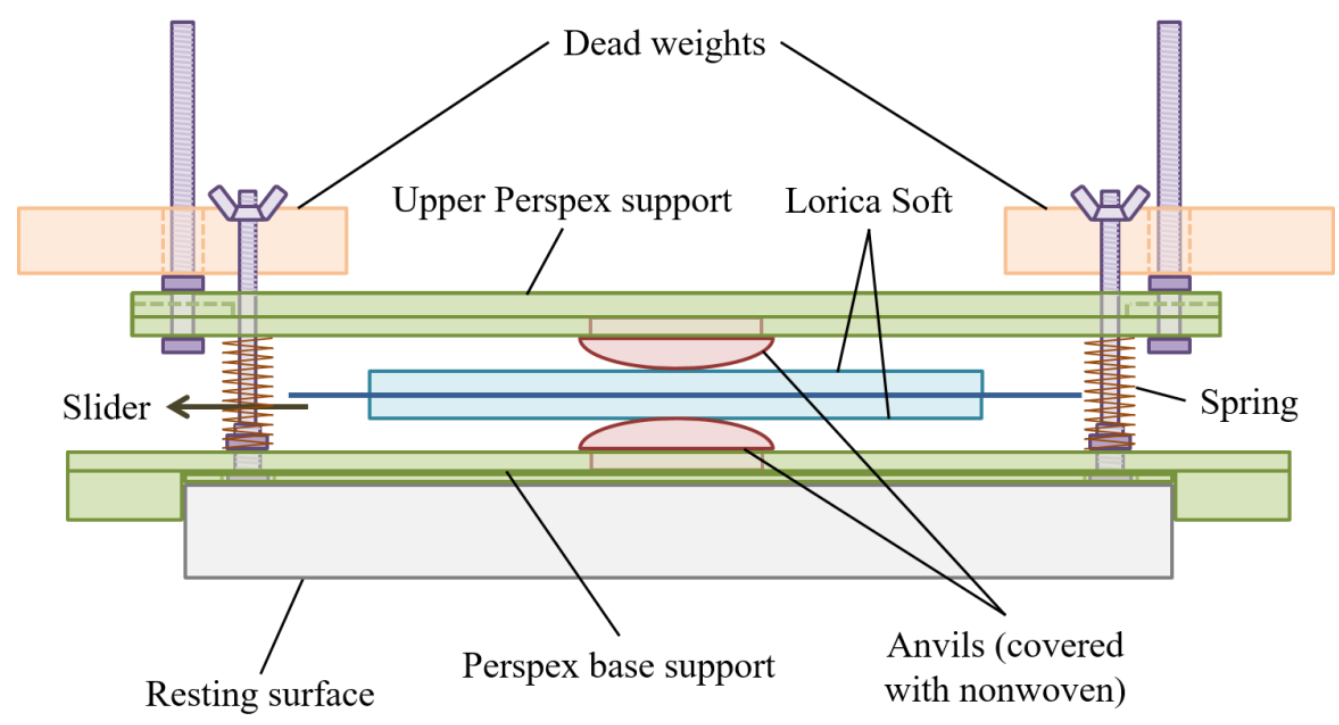

Figure 2. Diagram of apparatus used to measure friction between Lorica Soft (LS) and nonwoven fabrics, based on Cottenden and Cottenden (2013); not to scale - LS samples were $50 \mathrm{~mm}$ x $100 \mathrm{~mm}$ and the anvils were $26 \mathrm{~mm}$ in diameter.

For convenience in investigating a larger number of fabrics, just two applied loads $(2.65 \mathrm{~N}$ and $8.09 \mathrm{~N}$, corresponding to configurations $\tau \& \psi$ and $\chi$, respectively, in the paper by Cottenden and Cottenden (2013)) and one crosshead speed $\left(0.5 \mathrm{~mm} \cdot \mathrm{s}^{-1}\right)$ were used here. Nevertheless, the lower interface was always subject to a load of approximately $0.5 \mathrm{~N}$ greater than the upper interface due to the mass of the slider $(50.6 \mathrm{~g})$ between them, and the mean of the loads experienced by the two interfaces was used in all calculations. As the contribution of the slider mass to the mean normal force varied slightly during each friction cycle, references will simply be made to " $2.65 \mathrm{~N}$ anvils" and " $8.09 \mathrm{~N}$ anvils" - reflecting the intended applied loads, rather than the actual normal forces - from this point onwards, to avoid confusion.

The microstructure and associated mechanical properties of nonwovens can be highly anisotropic, varying - in particular - between the machine and cross-machine directions during manufacture. There may also be differences between the two faces, depending on the design and configuration of the rolls. 
Accordingly, for consistency in the current work, all nonwoven samples were mounted with their machine direction (somewhat arbitrarily) parallel to the direction of the tensometer pull, and all the samples of a given nonwoven were mounted with the same fabric face towards the Lorica Soft.

Another complexity to be addressed in running long series of measurements on the same fabric sample is that such nonwovens typically take one or two measurement cycles to wear in (and yield consistent data) and, after several more measurements, begin to wear out (Cottenden and Cottenden, 2013). For the current work, 10 repeat friction measurements were made under each load for each fabric, and data from the initial two repeats, corresponding to the wear-in period, were discarded before analysis (see Results). However, the surface integrity for the nonwoven fabrics was stable for the 10-cycle period. The same two pieces of Lorica Soft were used with all samples of fabric, but the data obtained were not thought to be affected by their repeated use. This was because Cottenden and Cottenden's combined preliminary and published data suggested no notable change in the Lorica Soft samples after extensive friction measurements.

\section{Results}

Figure 3 provides an example set of the 10 replicate traces of friction force against displacement for one fabric (SF16) with one of the two pairs of anvils $(2.65 \mathrm{~N})$. Plots were of similar form for all fabrics and both loads. Each curve exhibited an initial peak (corresponding to overcoming static friction) followed by a transition phase (for displacements up to not more than $12 \mathrm{~mm}$ ) before a quasi-constant dynamic friction force was reached, so justifying the decision to discard data for displacements up to $12 \mathrm{~mm}$ when calculating the mean dynamic friction force for a given replicate. The curve for the first replicate in a set of 10 - and sometimes the second - was higher than for subsequent replicates for all fabrics and both loads, but there was no systematic variation across replicates 3-10 (figure 4). In consequence, data from the first two replicates were discarded when mean friction forces for a given fabric and load were calculated.

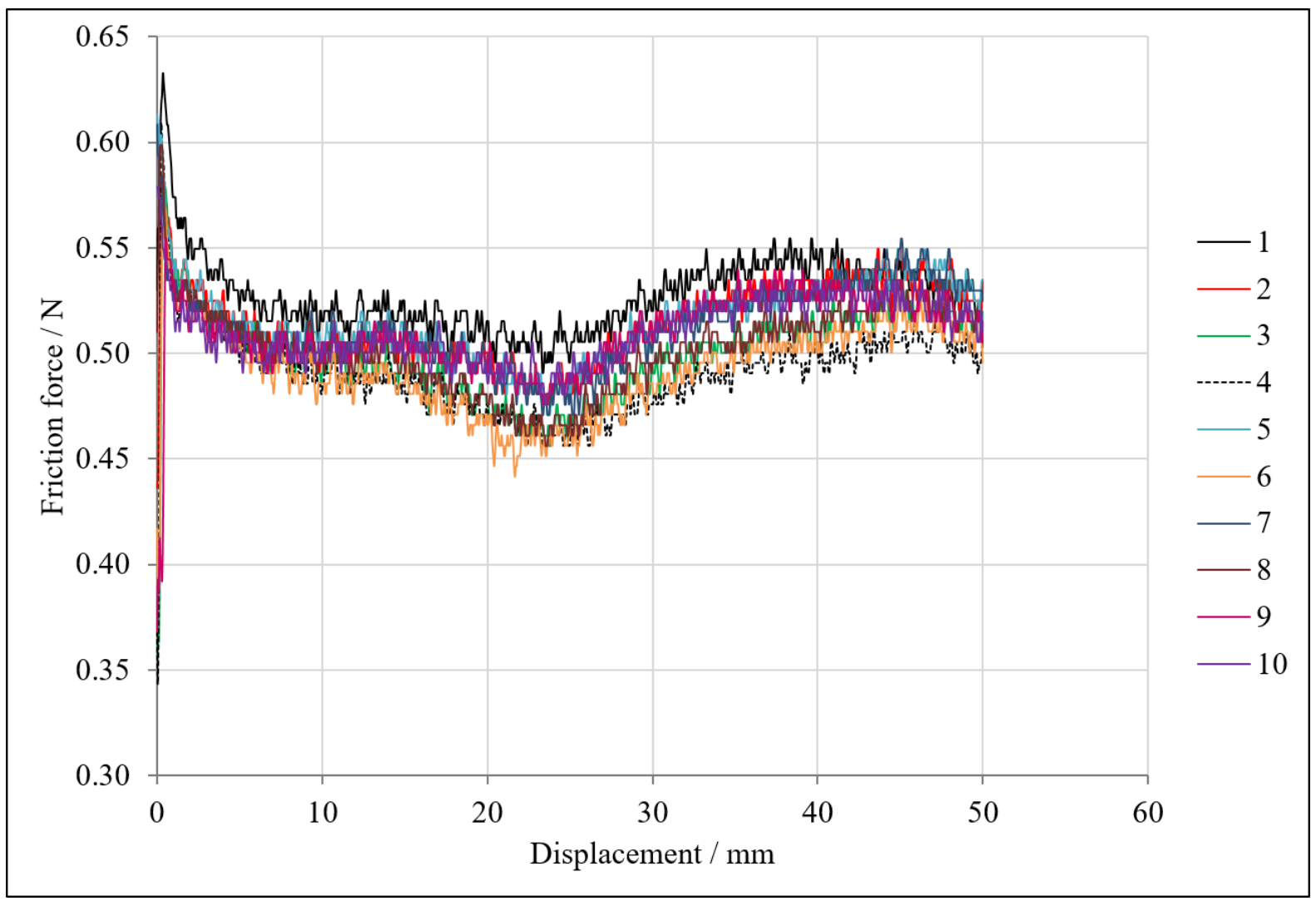

Figure 3. An example set of 10 replicate traces of friction force against displacement for nonwoven SF16 against Lorica Soft, with the $2.65 \mathrm{~N}$ anvils. All force values plotted are half of the measured tensometer values, representing the mean for the two nonwoven $\sim$ anvil Lorica Soft interfaces. 
Friction between a surrogate skin (Lorica Soft) and nonwoven fabrics used in hygiene products

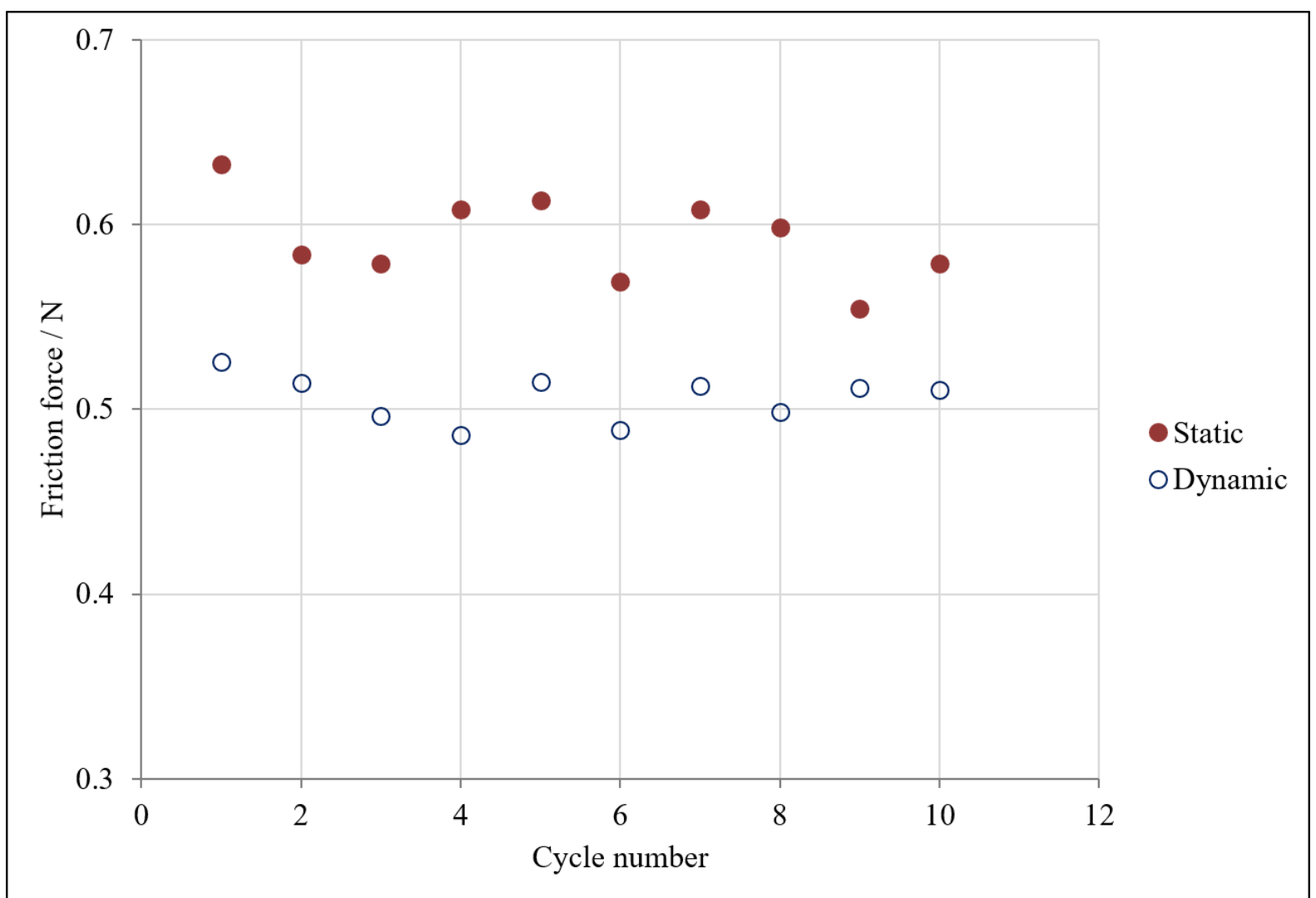

Figure 4. Static and dynamic friction forces measured for each cycle of friction between SF16 and Lorica Soft with the $2.65 \mathrm{~N}$ anvils.

The coefficient of static friction for each fabric under each of the two loads was calculated as the mean static friction force across replicates 3-10, divided by the load (corrected for the weight of the slider). For coefficients of dynamic friction, the mean dynamic friction force for each of replicates 3-10 was averaged and divided by the corrected load. Results are summarized in figure 5. Despite the considerable variety of fibre polymer and decitex, fabric area density and other variables exhibited by the 13 fabrics, their coefficients of friction against Lorica Soft were remarkably similar. Almost all of them had coefficients of static friction in the range 0.21-0.23, and coefficients of dynamic friction in the range 0.18-0.21. It is notable that all three of the fabrics that did not comprise just PP fibres had coefficients of friction falling outside the ranges of values for the PP fabrics. SF18, with its low decitex (15) bicomponent PP/PE fibres, low area density $\left(15 \mathrm{~g} . \mathrm{m}^{-2}\right)$ and low bonding area (12\%), had the lowest coefficients of friction of all the fabrics. At the other end of the range, SF3 - the only fabric with PET fibres - had the highest coefficients of friction, followed by SF14 with its mix of PP and cotton fibres.

The repeatability of measurements across replicates 3-10 for a given fabric and load was remarkably good (figure 5), with the coefficient of variation never exceeding the 5\% for static friction measurements on fabric SF3 using the $8.09 \mathrm{~N}$ anvils. Coefficients of friction with $2.65 \mathrm{~N}$ anvils and $8.09 \mathrm{~N}$ anvils were generally in good agreement, and the coefficient of friction from the $8.09 \mathrm{~N}$ anvils differed by less than 5\% from the corresponding value for $2.65 \mathrm{~N}$ anvils, for 19 of the 26 comparisons (static and dynamic friction for each of the 13 fabrics). The biggest difference was for SF15, for which the coefficient of dynamic friction with $8.09 \mathrm{~N}$ anvils was $12.6 \%$ higher than with $2.65 \mathrm{~N}$ anvils. In twelve of the comparisons, the coefficient of friction from $8.09 \mathrm{~N}$ anvils was lower than that from 2.65 $\mathrm{N}$ anvils, while the reverse was true for the other fourteen. 
Friction between a surrogate skin (Lorica Soft) and nonwoven fabrics used in hygiene products

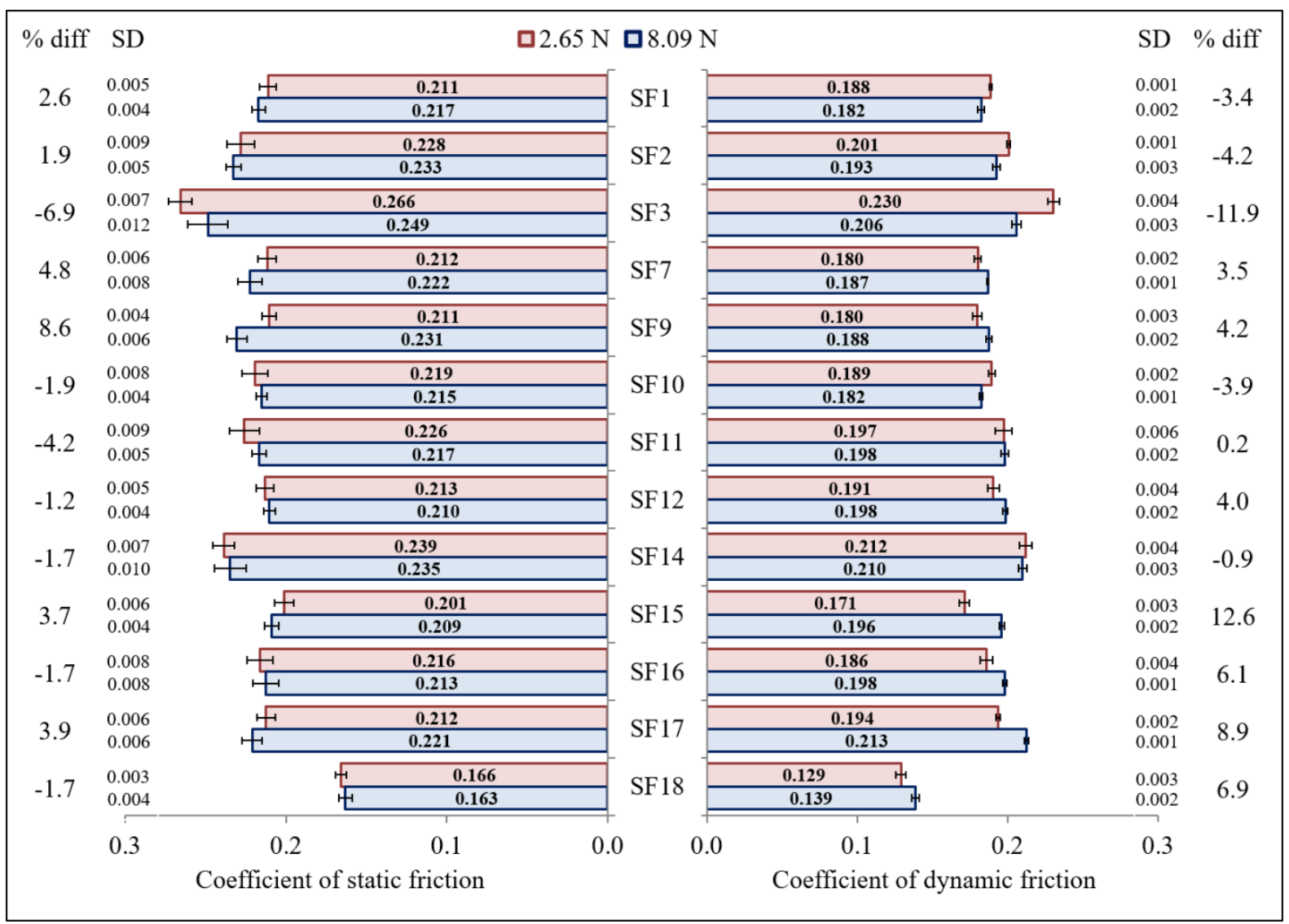

Figure 5. Mean (and standard deviation / SD) coefficients of static and dynamic friction across replicates 3-10 for each of the 13 nonwovens, with each pair of anvils $(2.65 \mathrm{~N}$ and $8.09 \mathrm{~N})$. The percentages by which coefficients of friction from $8.09 \mathrm{~N}$ anvils exceeded those from $2.65 \mathrm{~N}$ anvils are also given (\% diff).

\section{Discussion and conclusions}

Coefficients of friction measured under the two different loads were in good agreement with each other for all 13 fabrics, for both static and dynamic friction (figure 5); that is, Amontons' law was obeyed. Differences were generally less than 5\% (19/26 comparisons), with a maximum of $12.6 \%$, and were about as likely to be positive as negative: in 14/26 comparisons the coefficient of friction for $8.09 \mathrm{~N}$ anvils exceeded that for $2.65 \mathrm{~N}$ anvils, while the reverse was true for the remaining 12 comparisons (figure 5). Statistical testing (Wilcoxon signed rank test with continuity correction) revealed no significant systematic difference between coefficients of friction (static and dynamic) between the two loads, across the 13 fabrics. Although the differences were quite modest for any of the fabrics, they may seem large considering the excellent repeatability of the friction data from which they were calculated. However, there is another source of error to consider. For a given fabric, the measurements made under the two different loads used different test pieces of the same fabric and the comparison of data assumes them to have had identical properties. Yet it is known that the homogeneity of nonwoven fabrics can be poor so that test pieces taken from nearby locations on the same sample may vary considerably.

The inhomogeneity of these fabrics was not investigated in friction measurements with Lorica Soft but, in unpublished preparation for their earlier work, Cottenden and Cottenden (2013) did investigate the variation in friction properties across multiple samples of a PP nonwoven (DC6 in table 1) similar to those studied here, and using the same procedure. They made 3-5 repeat friction measurements using a particular load and crosshead speed, before replacing the fabric test-pieces with new ones and repeating the exercise. They then compared mean coefficient of friction values for the two different series. They made five such pairwise comparisons, using different loads and crosshead speeds and found differences between mean coefficients of dynamic friction of between $1.9 \%$ and $9.0 \%$. It is not known how typical 
the variability of DC6 was of the 13 fabrics studied here, but it is noteworthy that the differences in coefficients of dynamic friction found between nominally identical test pieces of their DC6 fabric were similar to those reported here for different samples of the same fabric tested under different loads (figure 5). This suggests that the (albeit limited) deviation from Amontons' law for a given fabric, shown in figure 5 (coefficients of friction varying with load), is attributable to variability in the fabrics from which test pieces were cut.

Despite the considerable variety of fibre polymer and decitex, and fabric area density and bonding area across the 13 fabrics, their coefficients of friction against Lorica Soft were remarkably similar, and especially so for the 10 fabrics comprising just PP fibres (figure 5). Differences in coefficient of static friction between any pair of fabrics comprising just PP fibres never exceeded $12.6 \%$, and never $15.7 \%$ for coefficient of dynamic friction. It is likely that these differences are largely attributable to the inhomogeneity of the fabrics since they are mostly of similar order to the differences (1.9-9.0\%) that Cottenden and Cottenden (2013) found, between multiple samples of the same fabric in their work, with a PP nonwoven similar to those studied here. If fibre decitex, fabric area density and bonding area $d o$ affect PP nonwoven friction properties, the impact appears to have been too subtle to rise convincingly above the noise in the data, likely to have been generated by inhomogeneity in the fabrics: varying fibre decitex (2.0-6.5), fabric area density (13-30 g. $\left.\mathrm{m}^{-2}\right)$ and bonding area (11-25\%) across the ranges exhibited by these ten PP fabrics had little effect on their dry friction properties with Lorica Soft.

The PET fabric (SF3) had significantly higher coefficients of static and of dynamic friction than the highest friction PP fabric (SF2) at each of the two test loads ( $p<0.005)$, while the PE/PP fabric (SF18) had significantly lower coefficients of friction than the lowest friction PP fabric $(\mathrm{SF} 15)\left(\mathrm{p}<10^{-8}\right)$. However, in both comparisons the fabrics differed in too many ways (table 1) for friction differences to be clearly attributable just to the choice of fibre polymer.

The work described here has been useful in showing that Amontons' law holds - at least, against Lorica Soft - for the friction properties of a wide range of nonwoven fabrics of the kind used to face incontinence pads, and it has yielded data that indicate the range of properties exhibited by these fabrics for the Lorica Soft model system. Perhaps surprisingly, the work shows that fibre decitex, and fabric area density and bonding area appear to have little effect on friction properties, at least over the ranges exhibited by the test fabrics. There is some evidence that making nonwovens using PET fibres may yield higher - and PE fibres, lower - coefficients of friction than using PP fibres, but more work is needed to separate out such confounding variables as fibre decitex and fabric area density. The next step is to investigate the friction properties of a subset of the fabrics against the skin of volunteers, first in the dry state and then in the wet to build a better understanding of friction between skin and incontinence pads in real use.

\section{Acknowledgements}

The funding of SCA Hygiene Products $\mathrm{AB}$ and the Engineering and Physical Sciences Research Council is gratefully acknowledged, as is the advice of Dr David Cottenden whose own work was foundational to that presented here.

\section{References}

Adams M J, Briscoe B J and Johnson S A 2007 Friction and lubrication of human skin Tribol. Lett. 26(3) 239-53

Berg R W 1988 Etiology and pathophysiology of diaper dermatitis Adv. Dermatology 3 75-98 Clarke-O'Neill S, Farbrot A, Lagerstedt Eidrup M-L, Cottenden A and Fader M 2015 Is it feasible to use incontinence-associated dermatitis assessment tools in routine clinical practice in the long-term care setting? J. Wound Ostomy Continence Nurs. 42(4) 379-88

Cottenden A M, Wong W K R, Cottenden D J and Farbrot A 2008a Development and validation of a new method for measuring friction between skin and nonwoven materials Journal of Engineering in Medicine 222 791-803 
Friction between a surrogate skin (Lorica Soft) and nonwoven fabrics used in hygiene products

Cottenden A M, Cottenden D J, Karavokiros S and Wong W K R 2008b Development and experimental validation of a mathematical model for friction between fabrics and a volar forearm phantom Journal of Engineering in Medicine 222 1097-106

Cottenden A, Bliss D, Buckley B, Fader M, Gartley C, Hayder D, Ostaszkiewicz J and Wilde M 2013 Management with Continence Products In ed P Abrams, L Cardozo, S Khoury and A Wein Incontinence Fifth edition (Health Publications Ltd.) p 1761

Cottenden D J and Cottenden A M 2013 A study of friction mechanisms between a surrogate skin (Lorica soft) and nonwoven fabrics J. Mech. Behav. Biomed. 28 410-26

Cua A B, Wilhelm K P and Maibach H I 1990 Frictional properties of human skin: relation to age, sex and anatomical region, stratum corneum hydration and transepidermal water loss Brit. J. Dermatol. 123(4) 473-9

Derler S, Schrade U and Gerhardt L-C 2007 Tribology of human skin and mechanical skin equivalents in contact with textiles Wear 263 1112-16

Derler S, Huber R, Feuz H-P and Hadad M 2009 Influence of surface microstructure on the sliding friction of plantar skin against hard substrates Wear 267 1281-8

Derler S and Rotaru G-M 2013 Stick-slip phenomena in the friction of human skin Wear 301 324-9

EDANA 2008 What Are Nonwovens? [Online]

Available at: $\quad$ http://www.edana.org/discover-nonwovens/what-are-nonwovens-

[Accessed: February 2012]

Elsner P, Wilhelm D and Maibach H I 1990 Frictional properties of human forearm and vulvar skin: influence of age and correlation with transepidermal water loss and capacitance Dermatologica 181(2) 88-91

Ersser S J, Getliffe K, Voegeli D and Regan S 2005 A critical review of the inter-relationship between skin vulnerability and urinary incontinence and related nursing intervention Int. J. Nursing Studies 42(7) 823-35

Gerhardt L-C, Mattle N, Schrade G U, Spencer N D and Derler S 2008a Study of skin-fabric interactions of relevance to decubitus: friction and contact-pressure measurements Skin Res. Technol. 14 77-88

Gerhardt L-C, Strassle V, Lenz A, Spencer N D and Derler S 2008b Influence of epidermal hydration on the friction of human skin against textiles Journal of the Royal Society Interface 5 1317-28

Gerhardt L-C, Schiller A, Müller B, Spencer N D and Derler S 2009a Fabrication, characterisation and tribological investigation of artificial skin surface lipid films Tribol. Lett. 34 81-93

Gerhardt L-C, Lenz A, Spencer N D, Münzer T and Derler S 2009b Skin-textile friction and skin elasticity in young and aged persons Skin Research and Technology 15 288-98

Gray M 2010 Optimal management of incontinence-associated dermatitis in the elderly Am. J. Clin. Dermatol. 11(3) 201-10

Hong K H, Kim S C and Kang T J 2005 Effect of abrasion and absorbed water on the handle of nonwovens for disposable diapers Text. Res. J. 75 544-50

Hunskaar S, Burgio K, Clark A, Lapitan M C, Nelson R, Sillen U and Thom D 2005 Epidemiology of urinary and faecal incontinence and pelvic organ prolapse In ed P Abrams, L Cardozo, S Khoury and A Wein Incontinence 3rd ed. Vol. 1 (Plymouth: Health Publications Ltd) pp 266, 268, 281

Kothari V K and Das A 1993 The compressional behaviour of spunbonded nonwoven fabrics J. Text. I. 84 16-30

Kwiatkowska M, Franklin S E, Hendriks C P and Kwiatkowski K 2009 Friction and deformation behaviour of human skin Wear 267 1264-73

Lyder C H, Clemes-Lowrance C, Davis A, Sullivan L and Zucker A 1992 Structured skin care regimen to prevent perineal dermatitis in the elderly J. Enterostomal Therapy Nursing 19(1) 12-16

Milsom I, Altman D, Cartwright R, Lapitan M C, Nelson R, Sillén U and Tikkinen K 2013 Epidemiology of Urinary Incontinence (UI) and other Lower Urinary Tract Symptoms (LUTS), Pelvic Organ Prolapse (POP) and Anal Incontinence (AI) In ed P Abrams, L Cardozo, S Khoury and A Wein Incontinence Fifth edition (Health Publications Ltd.) pp 28-30

Tomlinson S E, Lewis R, Liu X, Texier C and Carré M J 2011 Understanding the friction mechanisms between the human finger and flat contacting surfaces in moist conditions Tribol. Lett. 41 283-94

Veijgen N K, Masen M A and van der Heide E 2012 A novel approach to measuring the frictional behaviour of human skin in vivo Tribol. Int. 54 38-41 
Friction between a surrogate skin (Lorica Soft) and nonwoven fabrics used in hygiene products

Veijgen N K, Masen M A and van der Heide E 2013 Relating friction on the human skin to the hydration and temperature of the skin Tribol. Int. 49 251-62 